\title{
Uma proposta de tipologia para pesquisas de natureza interventiva
}

\author{
A typology proposal for action research
}

Paulo Marcelo Marini Teixeira ${ }^{1}$ • Jorge Megid Neto ${ }^{2}$

Resumo: O artigo é um ensaio teórico, estabelecendo reflexões sobre as Pesquisas de Natureza Interventiva (PNI) e sua aplicação no campo de pesquisa educacional, com especial atenção para aquelas produzidas na área de Educação em Ciências. Evidencia as múltiplas facetas assumidas pelas investigações articuladoras de ação e pesquisa, e, mais que isso, problematiza o uso vago e indiscriminado do termo Pesquisa-Ação. Com base em revisão de literatura, apresenta uma série de características para definição de projetos de pesquisa-ação, separando essa modalidade de outras possibilidades existentes entre as PNI. Adicionalmente, propomos uma matriz exibindo características básicas para definirmos com mais precisão as diferentes modalidades de PNI. A ideia é que a referida matriz ajudará a trajetória de estudantes, jovens pesquisadores e também pesquisadores mais experientes no enquadramento teórico-metodológico de seus projetos de investigação.

Palavras-chave: Pesquisa em educação. Educação em ciências. Métodos de pesquisa. Pesquisa-ação.

\begin{abstract}
This article is a theoretical essay that provides thoughts on action research and its application in the field of educational research, with special attention to that produced in Science Education. It shows the multiple facets assumed by research studies linking action and research, and, furthermore, questions the vague and indiscriminate use of the term Action-Research. Based on a review of the literature, it presents a number of characteristics to define action-research projects, separating this modality from other possibilities. In addition, it proposes a matrix showing basic characteristics in order to more precisely define the different action-research modalities. The expectation is that this matrix will help students and young researchers, as well as more experienced researchers, in the theoretical-methodological classification of their research projects.
\end{abstract}

Keywords: Educational research. Science education. Research methodology. Action-research.

\footnotetext{
${ }^{1}$ Universidade Estadual do Sudoeste da Bahia (UESB), Departamento de Ciências Biológicas, Jequié, BA, Brasil. E-mail: <paulommt@hotmail.com>.

${ }^{2}$ Universidade Estadual de Campinas (Unicamp), Faculdade de Educação, Campinas, SP, Brasil.
} 


\section{Introdução}

Intervenção: ato de intervir; interferência; intercessão; mediação; tomar parte com a intenção de influir no desenvolvimento ou no desfecho de uma determinada situação (FERREIRA, 1999; HOUAISS; VILLAR, 2009; MICHAELIS, 1998). Tais ideias são encontradas em dicionários, sendo associadas à definição formal da palavra intervenção. Assim, podemos inferir, entre outras coisas, que as chamadas pesquisas de intervenção, ou melhor, em nossa opção, as Pesquisas de Natureza Interventiva, seriam práticas que conjugam processos investigativos ao desenvolvimento concomitante de ações que podem assumir natureza diversificada. Neste texto, nosso argumento nuclear é o de que o termo Pesquisas de Natureza Interventiva (PNI) pode ser utilizado com vantagem para enquadrar uma multiplicidade de modalidades de pesquisa caracterizadas por articularem, de alguma forma, investigação e produção de conhecimento, com ação e/ou processos interventivos.

Um primeiro aspecto a salientar é relativo ao termo intervenção. Há quem associe essa ideia a uma perspectiva negativa, no sentido de ingerência intrusa e autoritária em processos, pessoas, grupos e instâncias sociais. Não é esta a posição aqui adotada, porque, a nosso ver, intervenções podem ter caráter positivo e altruísta, como no caso das intervenções cirúrgicas que livram pacientes de seus problemas de saúde; ou nos exemplos bem documentados pelo noticiário jornalístico de intervenções humanitárias que, se não resolvem, pelo menos, mitigam e aliviam a situação de sofrimento que afeta populações atingidas por guerras, pandemias, desastres naturais e outras mazelas sociais. Neste sentido, considerando o contexto educacional, estamos alinhados a Chizzotti (2006), Dionne (2007), Dubost (1987), e Thiollent (2011), autores que valorizam as Pesquisas de Natureza Interventiva como modalidades de investigação úteis para gerar conhecimentos, práticas alternativas/inovadoras e processos colaborativos. Além disso, podemos testar ideias e propostas curriculares, estratégias e recursos didáticos, desenvolver processos formativos, nos quais, os pesquisadores e demais sujeitos envolvidos, atuam na intenção de resolver questões práticas sem deixar de produzir conhecimento sistematizado. Outro ponto a observar é a abundante literatura encontrada quando buscamos informações sobre as PNI. Isso parece ser resultado da confluência de pelo menos dois fatores: (i) o aumento da popularidade e do emprego dessas modalidades de investigação (EL ANDALOUSSI, 2004; THIOLLENT, 2011; TRIPP, 2005; ZEICHNER; DINIZ-PEREIRA, 2005); (ii) os discursos, cada vez mais incisivos, fomentando a tendência para que as investigações ofereçam respostas para problemas práticos e, no caso da pesquisa educacional, incluindo a produção na área de Educação em Ciências, que os resultados tenham influxo na prática e na melhoria das condições de ensino e aprendizagem em nossas escolas (ANDRÉ, 2006; GATTI, 2000; MIRANDA; RESENDE, 2006).

Por fim, vale sublinhar que o crescimento do movimento em prol da realização de PNI gerou também um fenômeno interessante: a pluralidade de terminologias utilizadas por pesquisadores, educadores e especialistas na área de metodologia de pesquisa para se referir a esse conjunto de processos investigativos. Neste último aspecto, em particular, quando focalizamos as pesquisas educacionais, encontramos amplo espectro de denominações (Figura 1), por vezes, empregadas livremente, de forma vaga e sem o devido cuidado, o que, a nosso ver, cria um quadro de confusão generalizada (TRIPP, 2005), ou como diria Chizzotti (2006), uma espécie de sincretismo ambíguo; ou ainda um mosaico (BARBIER, 2007; FRANCO, 2005; MIRANDA; RESENDE, 2006), em que temos a utilização livre de certas definições e rótulos, 
sem o devido cuidado com os pressupostos epistemológicos, teóricos e metodológicos, além de concepções de mundo e de educação que deveriam sustentar as nossas escolhas quando desenvolvemos um trabalho de pesquisa (CHIZZOTTI, 2006; GHEDIN; FRANCO, 2008).

Figura 1. Um mosaico com diferentes denominações utilizadas para as chamadas Pesquisas de Natureza Interventiva (PNI)

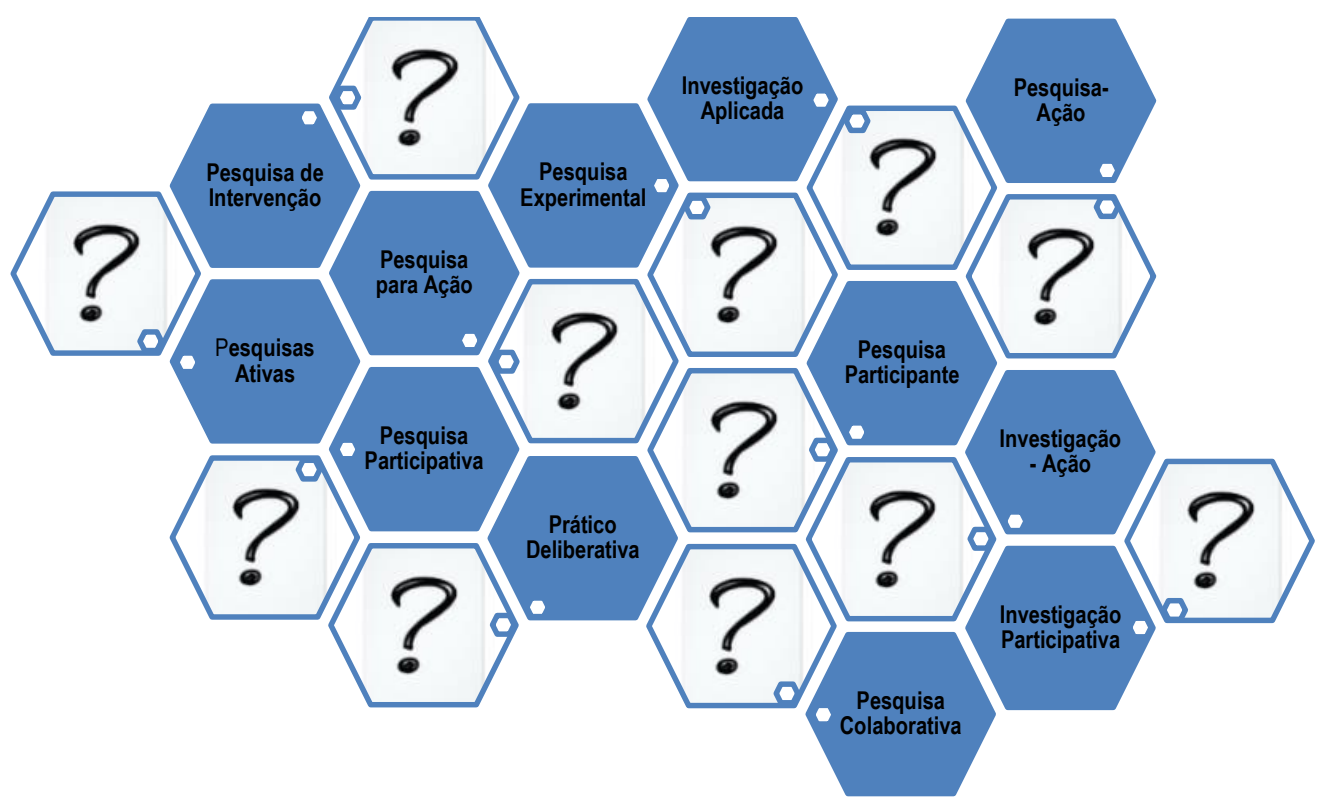

Obs.: As interrogações expressam as diversas outras denominações encontradas na literatura.

Fonte: elaborada pelo autores.

Por exemplo, para El Andaloussi (2004, p. 101), a "confusão conceitual que cerca a pesquisa-ação não ajuda a construir uma definição clara e operacional" dessa modalidade de investigação. Além do mais, não podemos ignorar o fato de que tal multiplicidade de denominações traduz, em certo sentido, "opções ora diferentes e convergentes, ora desiguais ou mesmo divergentes” (BRANDÃO, 2006, p. 34).

Explicitadas essas considerações iniciais, o objetivo deste texto é estabelecer reflexões sobre as pesquisas de natureza interventiva. Ao examinar a literatura, procuramos luz na confusão estabelecida, identificando distinções e similitudes entre as diferentes formas de conduzir projetos de investigação articuladores da dimensão da pesquisa acadêmica e científica com o desenvolvimento de ações, projetos e outras práticas. Nossa proposta é clara neste sentido: sugerir uma espécie de matriz para organizar nosso pensamento e também nossas práticas. Com efeito, o texto se coloca como tentativa de proposição de uma síntese integrativa, baseada nos trabalhos arrolados junto a literatura pertinente, com a consequente construção de uma matriz 
de características básicas para definirmos com mais precisão diferentes modalidades de PNI. Se formos bem-sucedidos nessa empreitada, entendemos que o texto ajudará a trajetória de estudantes, jovens pesquisadores e também pesquisadores mais experientes no enquadramento teórico-metodológico de seus projetos de investigação.

Não há dúvida que, entre todas as denominações listadas na Figura 1, o termo Pesquisa-Ação é de longe o mais empregado em nossas dissertações, teses, artigos, livros e outras publicações. É o que acontece, por exemplo, nos trabalhos da área de Educação em Ciências em nosso país. Há uma verdadeira polissemia em torno da ideia de pesquisa-ação (BRANDÃO, 2006; EL ANDALOUSSI, 2004) $)^{3}$. Talvez parte da confusão aludida nas linhas anteriores diga respeito ao emprego indiscriminado do referido "rótulo". Por vezes, o termo pesquisa-ação (PA) é aplicado para todo e qualquer projeto a envolver pesquisa caminhando junto com intervenção. Neste sentido, caberia perguntar: os autores de trabalhos acadêmicos, ao mencionarem a adoção de uma PA explicitam autores, referenciais e outras informações para sustentar a escolha de sua modalidade investigativa? Nosso palpite é que em parte dos casos isso não acontece. Assim, outro argumento defendido neste texto é que a noção de PA adotada genericamente em parte das pesquisas e estudos acadêmicos deveria ficar restrita a dois formatos que evidenciaremos mais adiante. Os outros, a nosso ver, não se enquadram no perfil de PA consagrado pelos principais autores dedicados à teorização sobre o assunto e, portanto, devem ser separados em outras categorias como forma de organizar nossas ideias e práticas.

\section{Breve histórico}

É tarefa complexa buscar as origens da ideia de PA. O termo ganha notoriedade em trabalho publicado em 1946, por Kurt Lewin. Com efeito, para muitos autores, Lewin, com seus estudos de action-research, é uma espécie de pai da Pesquisa-Ação ${ }^{4}$ ou, pelo menos, é personagem importante quando tratamos de suas origens (BARBIER, 2007; BRANDÃO; STRECK, 2006; EL ANDALOUSSI, 2004; FRANCO, 2005; GHEDIN; FRANCO, 2008; TRIPP, 2005). Já para McKernan (1996), a relevância de Lewin para a PA não está no pioneirismo, mas sim no trabalho de sistematização da teoria sobre esse tipo de pesquisa, de modo que a pesquisa-ação passou a ganhar mais destaque e status científico junto às Ciências Sociais. Isso não significa que a ideia de associar pesquisa e ação apareça somente em meados do século passado. Existem várias menções à referida ideia em trabalhos anteriores, inclusive antes de Kurt Lewin, em estudos

\footnotetext{
${ }^{3}$ Ainda a esse respeito, Thirion (1980 apud EL ANDALOUSSI, 2004, p. 84) menciona o fenômeno da "dispersão semântica da pesquisa-ação", decorrente da polissemia dos termos empregados para representá-la. A ideia de polissemia se faz presente também na análise proposta por Brandão (2006) ao examinar aspectos relativos à pesquisa-participante.

${ }^{4}$ A Pesquisa-Ação proposta por K. Lewin está associada a uma investigação "cuja meta é a transformação de determinada realidade, implicando diretamente a participação dos sujeitos envolvidos no processo, atribuindo ao pesquisador os papéis de pesquisador e de participante e ainda sinalizando para a necessária emergência dialógica da consciência dos sujeitos, na direção da mudança de percepção e de comportamento" (GHEDIN; FRANCO, 2008, p. 216).
} 
realizados por sociólogos no final do século XIX e também no início do século XX, como nos casos citados por David Tripp: o trabalho de John Collier, relacionado às relações inter-raciais em nível comunitário; o livro Research for Teachers, publicado por Buckingham, em 1926 (SELENER, 1997 apud TRIPP, 2005); as referências a John Dewey sobre o conceito de reflexão e suas convergências com princípios adotados pela PA aplicada à formação de professores (práticos reflexivos) $)^{5}$. Algumas pessoas associam a PA e a pesquisa participante "aos trabalhos ao redor da enquete operária de Karl Marx” (BRANDÃO; STRECK, 2006, p. 22).

René Barbier (BARBIER, 2007, p. 25) destaca dois períodos significativos na trajetória tortuosa da pesquisa-ação: (i) um americano, ligado a emergência e consolidação da PA na época anterior à Segunda Guerra Mundial e durante os anos 1960; (ii) um europeu e canadense, ligado à radicalização política e existencial da PA, a partir da década de 1960.

No caso da América Latina, especial importância deve ser atribuída para os estilos participativos de investigação social encontrados nas ideias que sustentam a educação popular, a Teologia da Libertação e o trabalho de alguns grupos ligados a movimentos populares. Neste contexto, nomes importantes são Leonardo Boff, Paulo Freire, Florestan Fernandes, Camilo Torres e Orlando Fals Borda, entre outros (BARBIER, 2007; BRANDÃO; STRECK, 2006).

Conforme assevera Tripp (2005, p. 445) "é pouco provável que algum dia venhamos a saber quando ou onde teve origem esse método", mas é importante salientar que não é uma prática recente, seja no campo mais estritamente acadêmico, seja em outras áreas, inclusive aquelas mais distantes das pesquisas em Ciências Sociais. De fato, para além do campo das pesquisas educacionais, menções às PNI e, especialmente, à PA, são encontradas em diferentes setores com aplicações na economia, indústria, recursos humanos, estudos organizacionais, psicanálise, sociologia, medicina e outras ciências da saúde, ciências ambientais etc. Segundo Thiollent (2011) as áreas mais tradicionais onde encontramos aplicações da PA são educação, formação de adultos, serviço social, extensão e comunicação rural. Já para Brandão e Streck (2006, p. 22), a pesquisa nessa modalidade surgiu em diferentes lugares, originando-se de diversas práticas sociais, com a articulação de diferentes referências teóricas e alternativas metodológicas, além de assumir, frequentemente, finalidades desiguais.

Após a ideia original de Lewin, podemos dizer que houve um período de disseminação, diversificação e fragmentação das propostas de PA, fundamentadas em diferentes pressupostos teóricos e metodológicos, muitas vezes, descaracterizando a pesquisa-ação de suas raízes epistemológicas. Aparecem modelos amparados em parâmetros positivistas, convivendo com outros alinhados a propostas funcionalistas e, por fim, há também as propostas que simplificaram em demasia a ideia original de Lewin, a ponto de, nesses casos, simplesmente não podermos mais falar em pesquisa-ação. O corolário para essa situação é o seguinte: nem toda pesquisa de naturez̧a interventiva pode ser caracteriz̧ada como Pesquisa-Ação. (EL ANDALOUSSI, 2004; FRANCO, 2005; GHEDIN; FRANCO, 2008).

\footnotetext{
${ }^{5}$ Sobre Dewey e pesquisa-ação ver El Andaloussi (2004).
} 
Brandão (2006) organiza as diversas possibilidades encontradas historicamente para o que ele chama de pesquisa participante em duas tradições. Uma é de origem europeia e americana e outra associada ao perfil que os projetos latino-americanos assumiram a partir das experiências pioneiras de Orlando Fals Borda e de Paulo Freire entre os anos de 1970 e 1980. Neste caso, as ações são marcadas pela sua vinculação com os movimentos sociais e populares e por projetos preocupados com a transformação social emancipatória (BRANDÃO, 2006, p. 21).

No caso da pesquisa educacional, a pesquisa-ação passa a ganhar terreno nos EUA por meio dos trabalhos de Stephen Corey e outros autores no período posterior à segunda grande guerra, a partir dos anos 1950; na Inglaterra, devemos salientar o trabalho de Lawrence Stenhouse com a defesa de ideias que associavam ensino e pesquisa sob responsabilidade dos professores. Segundo Franco (2005, p. 488), já em fins do século XX, há a tentativa de recuperar a concepção original de PA forjada nos anos 1970. Este momento histórico marca a incorporação de elementos da perspectiva dialética e dos fundamentos da Teoria Crítica, sobretudo aquela inspirada nos trabalhos de Jürgen Habermas. Boa parte desses trabalhos estão vinculados a projetos alinhados ao problema da formação de professores. Esse processo é marcado pelas contribuições de L. Stenhouse, J. Elliott e C. Aldeman, significando uma reaproximação da PA com seu estatuto epistemológico, e representando a ideia de que os professores poderiam atuar como pesquisadores em seu próprio campo de trabalho. De todo o modo, o processo de disseminação das pesquisas que articulam ação e investigação não aconteceu sem problemas, já que o "conceito de pesquisa-ação representa um veio privilegiado para a discussão de um dos maiores impasses enfrentados pelos educadores: a relação entre teoria e prática" (MIRANDA; RESENDE, 2006). Além disso, temos a profusão de conceitos mencionada anteriormente, e até movimentos de rejeição a essa modalidade de pesquisa, com o argumento de que, em muitos casos, por conta da exacerbação da atenção sobre a prática, acaba-se hipertrofiando a dimensão intervencionista, o que a nosso ver, pode levar ao ativismo ${ }^{6}$, ao praticismo, à manipulação política, ao extensionismo acrítico (prestação de serviço), caracterizados pela falta de preocupação com a dimensão cognitiva (geração de conhecimentos). Com efeito, em tais casos a dimensão da pesquisa acaba minimizada a perigosos limites, a ponto de colocar em risco a própria natureza acadêmica desses trabalhos. Nesse contexto, vale a advertência formulada por Michel Thiollent: "às vezes chega-se a muita participação e a pouco conhecimento" (THIOLLENT, 2011, p. 26).

Por fim, cabe mencionar o problema da "radicalização" esgrimido por alguns autores que escrevem sobre pesquisa-ação. Para nós, quando mencionamos a questão da radicalização no processo de disseminação e consolidação da PA, precisamos pensar em pelo menos duas variantes. A primeira refere-se à radicalização epistemológica, tendência acentuada na Inglaterra, França e Canadá durante os anos 1970, em processo que estabeleceu uma espécie de rompimento da pesquisa-ação em relação às Ciências Sociais instituídas (BARBIER, 2007). Porém, consideramos também a ideia de uma radicalização política, balizada pela posição dos autores latino-americanos já citados no contexto deste trabalho. Neste caso, vale o posicionamento da PA como forma de construir projetos de ação-pesquisa engajada (pesquisa participante), situadas no contexto de

\footnotetext{
${ }^{6}$ Em relação aos riscos associados ao ativismo, praticismo, etc. ver Demo (2004) e Miranda e Resende (2006).
} 
luta contra a opressão e a desigualdade social, pela emancipação popular e construção de uma sociedade mais justa, democrática e igualitária (BRANDÃO; STRECK, 2006; DEMO, 2004).

\section{Pesquisa-Ação como uma parte das Pesquisas de Natureza Interventiva}

Para dirimir os problemas apontados na parte inicial do texto, a saída pode estar na adoção de uma matriz mais abrangente de PNI. Nesta matriz, a pesquisa-ação constitui apenas uma fração dos possíveis trabalhos aglutinados nas PNI, sendo caracterizada segundo pressupostos encontrados na própria literatura, sobretudo em autores consagrados pela abordagem do tema. Todos os elementos da matriz convergem no sentido de aliarem pesquisa e intervenção e são considerados igualmente relevantes e necessários. Com efeito, não é o caso de estabelecer análises valorativas sobre qual tipo de pesquisa é mais ou menos indicado no contexto da prática investigativa, sobretudo quando pensamos nas contribuições para as áreas de Educação e Educação em Ciências, nosso campo de interesse mais imediato. Partimos do princípio de que todas as modalidades são relevantes para diagnosticar e descrever nossos problemas, identificar possibilidades de avanço no conhecimento, testar teorias e aprimorar práticas vinculadas à formação de professores e ao ensino-aprendizagem propriamente dito. Deste modo, um desdobramento possível de nosso trabalho está na tentativa de estruturar uma classificação sistematizada para essas modalidades de investigação, trabalho que a nosso ver, ainda estava por ser feito, considerando a profusão de termos e equívocos inevitáveis que aparecem nos estudos acadêmicos realizados, em particular, nas teses e dissertações, mas também nos artigos publicados em periódicos das referidas áreas.

Essa não é uma tarefa original. Tentativas de classificação para as genericamente chamadas pesquisas-ações (pesquisa participante, pesquisas de intervenção, etc.) já foram formuladas anteriormente. Entretanto, elas mostram "a quase impossibilidade de se estabelecer uma listagem confiável das diversas abordagens e alternativas" (BRANDÃO, 2006, p. 36). Dois trabalhos nessa linha podem ser encontrados em Gajardo (1986) e Silva (1991). Nos casos apontados, temos tentativas de classificação que deixam de fora uma série de outras pesquisas de natureza interventiva, sobretudo aquelas que não se enquadram nos modelos inspirados no trabalho de Kurt Lewin e nas variantes latino-americanas e europeias de pesquisa-ação. Além disso, apesar de reconhecermos as dificuldades e limitações inerentes à construção desses sistemas classificatórios, e de não pretendermos desenvolver uma tipologia pronta e acabada, defendemos que há a necessidade de dissipar esse estado de confusão conceitual, buscando mais precisão no emprego de termos essenciais para a definição teórico-metodológica das pesquisas que estamos desenvolvendo. Com efeito, pensando especialmente nas pesquisas realizadas na área educacional, além da pesquisa-ação, outras modalidades de PNI podem ser encontradas nas pesquisas experimentais e quase-experimentais, nas pesquisas de aplicação e análise de processos didáticos, nas chamadas investigações do tipo "pesquisa \& desenvolvimento" e, por fim, nas pesquisas realizadas pelos professores sobre a sua própria prática. Nossa experiência, ligada ao desenvolvimento de pesquisas do Estado da Arte na área de Educação em Ciências, sobretudo nas análises que temos produzido sobre os estudos focalizando o Ensino de Biologia, atestam, ainda que preliminarmente, a existência dessa diversidade de trabalhos. A Figura 2, apresentada na sequência, traz a matriz, isto é, um esquema esboçado para ilustrar as diversas possibilidades identificadas no conjunto mais abrangente das Pesquisas de Natureza Interventiva (PNI). 
Figura 2. Matriz: uma tipologia para as Pesquisas de Natureza Interventiva (PNI)

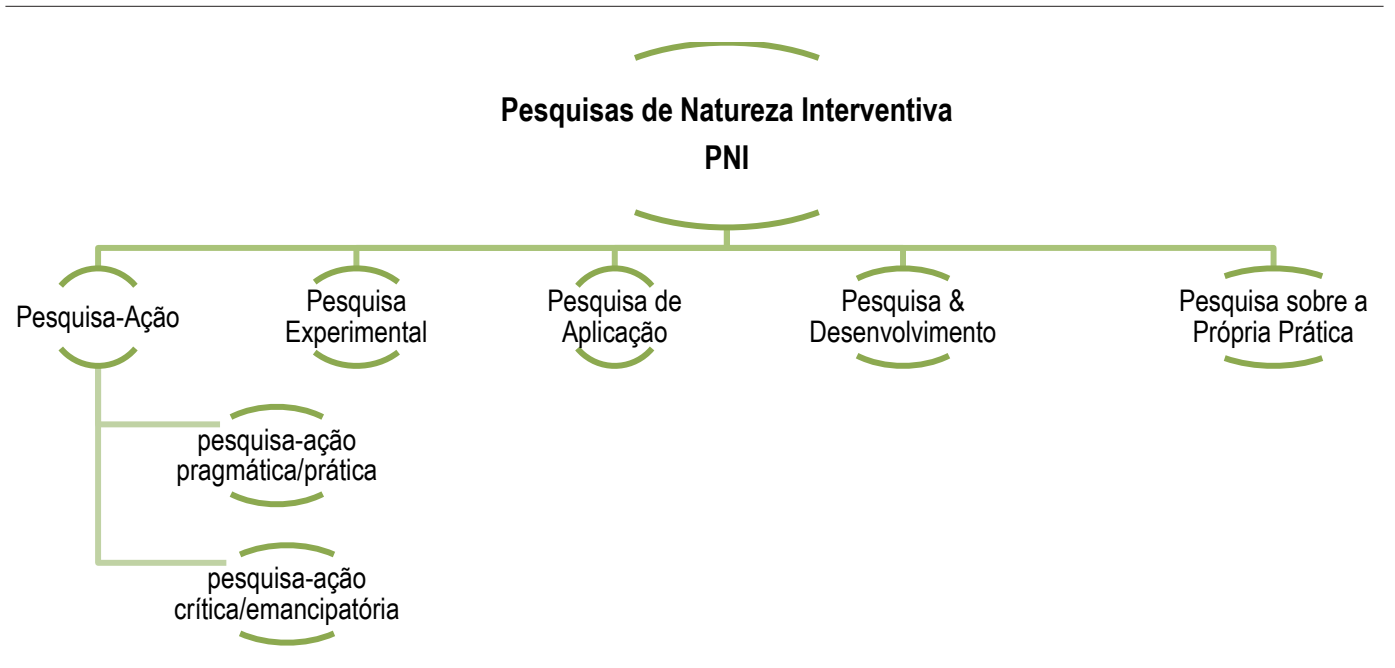

Fonte: elaborado pelos autores.

Definiremos no próximo item do texto, com base na literatura, o que entendemos por PA. Sem desconsiderar a profusão de ideias, matrizes e tradições de pensamento que cercam a noção de PA, entendemos ser fundamental identificar um núcleo de características básicas para delinearmos como pode ser minimamente enquadrada uma investigação dessa natureza. $\mathrm{Na}$ seção seguinte, dedicaremos espaço para as outras modalidades de PNI elencadas na matriz da Figura 2, procurando mostrar brevemente a especificidade de cada uma delas conforme a descrição das peculiaridades inerentes ao seu desenvolvimento, indicando adicionalmente autores que podem ser de interesse para os leitores que desejam aprofundar seus conhecimentos sobre cada uma dessas possibilidades.

\section{Caracterizando Pesquisa-Ação}

Mas afinal, de acordo com a literatura arregimentada para a construção deste artigo, o que configuraria uma Pesquisa-Ação? A literatura não é uníssona neste ponto. As diversas correntes encontradas passam pelo trabalho original de Kurt Lewin; pela versão europeia, preocupada com a questão do aprimoramento técnico dos práticos e pela análise institucional; temos ainda a vertente representada pelos autores australianos ao retomarem atenções para a Teoria Crítica e; por fim, algumas correntes Latino-Americanas, buscando na pesquisa-ação e/ ou pesquisa participante, instrumentos de emancipação e transformação social (BARBIER, 2007; CARR; KEMMIS, 1986; EL ANDALOUSSI, 2004; THIOLLENT, 1999). De qualquer forma, uma boa síntese é encontrada no trabalho proposto por Hugon e Seibel (1988 pud BARBIER, 2007, p. 17). Para eles a pesquisa-ação é definida da seguinte forma: "Trata-se de pesquisas nas quais há uma ação deliberada de transformação da realidade; pesquisas que possuem duplo objetivo: transformar a realidade e produzir conhecimentos relativos a essas transformações" (HUGON; SEIBEL, 1988 apud BARBIER, 2007, p. 17). 
Em qualquer desses casos, a PA rejeita noções positivistas, configurando-se como modalidade de investigação que pressupõe a explicitação dos valores pessoais e práticos envolvidos no processo investigativo e que, dependendo de como for encarada, pode significar forma totalmente distinta para se conceber e desenvolver pesquisas em Ciências Humanas e Sociais (BARBIER, 2007; EL ANDALOUSSI, 2004; FRANCO, 2005; GREENWOOD; LEVIN, 2006; MORIN, 2004). Tal posição foi definida a partir de uma forte crítica à prática científico-acadêmica ortodoxa, traduzindo-se numa ruptura epistemológica em relação aos cânones da pesquisa tradicional. Como foi dito, a perspectiva de crítica ao positivismo problematiza diversas questões, algumas das quais relacionadas às relações entre sujeito e objeto e, entre teorias e práticas; aos problemas associados a pressupostos ligados às noções de neutralidade, objetividade/subjetividade e de verdade na prática da pesquisa; além de valorizar o emprego de categorias interpretativas durante o processo de análise de dados e de geração do conhecimento científico e suas implicações para o tecido e as práticas sociais (BARBIER, 2007; CARR; KEMMIS, 1986; FRANCO, 2005).

Franco (2005, p. 489-491) menciona que a PA pode ser norteada por três dimensões: (i) ontológica: referente à natureza do objeto a ser pesquisado, almejando conhecer a realidade objeto de interesse, foco da pesquisa, de forma a transformá-la; (ii) metodológica: referente à relação sujeito-conhecimento. Notamos aqui, com mais intensidade, a aversão das propostas de PA aos cânones positivistas, pois exige-se um mergulho na intersubjetividade dos diversos participantes, uma relação de interação horizontal entre pesquisadores e sujeitos, e a recusa da neutralidade, apostando suas fichas numa perspectiva dialética de ação-reflexão; (iii) epistemológica: referente aos processos de conhecimento utilizados pelos pesquisadores. Implica a utilização de uma metodologia de trabalho articuladora de práticas dialógicas e participativas, flexíveis e ajustáveis ao longo do processo, considerando as etapas de espirais cíclicas: planejamento, ação, reflexão, pesquisa, ressignificação, replanejamento, etc.

Vale chamar atenção para o seguinte aspecto: a referida incompatibilidade entre a PA e a pesquisa tradicional, inspirada em pressupostos positivistas, não pode significar desenvolver uma espécie de investigação de segunda categoria, negligenciadora de padrões mínimos pactuados e exigidos dentro de um determinado campo de pesquisa. Neste sentido, marcamos a seguinte posição: PA não pode representar renúncia à produção de conhecimento, marcada mais por ativismo do que por produção de conhecimentos sistematizados. Entendemos que a mediação teórico-conceitual deve perpassar todas as etapas de desenvolvimento dos projetos, de tal sorte que PA não deveria significar a adoção de posturas anticientíficas, espontaneítas, imediatistas, dogmatistas, partidaristas e populistas (DEMO, 2004; DIONNE, 2007; THIOLLENT, 2011). Assim, é mister sublinhar que, em projetos de PA a dimensão da pesquisa não pode ser secundarizada em relação à ação. Ambas devem ser articuladas dialeticamente para, como assinala Thiollent (2011), garantir pesquisa que, sem se confundir com o positivismo, atenda critérios metodológicos e epistemológicos pactuado pela pesquisa social de caráter científico e não coloque sob suspeição o caráter acadêmico-científico desses trabalhos.

A maioria dos autores menciona a meta de transformação da realidade ou mudança social, na qual um projeto é desenvolvido, geralmente considerando situações sociais problemáticas (BOGDAN; BIKLEN, 2010; GHEDIN; FRANCO, 2008; THIOLLENT, 2011). Um problema neste ponto é que, nem sempre, o alcance desse tipo de transformação é explicitado e, em tais casos, não fica claro se tais mudanças sociais são projetadas mirando um plano micro, 
intermediário ou em macro escala. Também nem sempre fica clara a natureza da transformação desejada: podemos encontrar projetos em que se logram mudanças práticas, como diagnosticar e resolver problemas, mobilizar grupos para determinadas situações específicas de interesse, levar indivíduos e grupos a tomadas de posição, conscientização, etc. Em outros casos o estágio de transformação pretendido é mais complexo, envolvendo processos de diagnóstico, análise e tomada de posição em relação a problemas sociais mais amplos.

De toda forma, duas variantes são claramente visualizadas. Em parte dos casos, a PA tem caráter crítico-emancipatório, em outra, talvez englobando as situações mais frequentes, centra-se em questões de natureza mais técnica, prática ou pragmática (investigação-ação, pesquisa-ação colaborativa). Thiollent (2011, p. 105) vislumbra basicamente essas duas possibilidades para a PA: uma de orientação crítico-emancipatória e outra de orientação pragmática. O autor caracteriza essas duas possibilidades da seguinte forma:

\begin{abstract}
Na concepção das práticas educativas ou políticas, os partidários da PA adotam frequentemente uma orientação crítica, mais ou menos radical, voltada para a conscientização ou para a mobilização popular. Ao passo que, entre os partidários da PA nos contextos organizacional e tecnológico, a orientação é mais "acomodada", procurando transformações satisfatórias e compatíveis com a adaptação e o funcionamento das organizações existentes (THIOLLENT, 2011, p. 105).
\end{abstract}

Em verdade, quando Thiollent menciona a PA educacional está se referindo a concentração de estudos realizados na Educação de Adultos e na Educação Ambiental (THIOLLENT, 2011, p. 120). Marcela Gajardo parece compartilhar das ideias de Thiollent ao afirmar que, ao invés de caracterizar a ciência "como uma atividade que não assume [e] nem explicita suas opções frente ao tipo de sociedade em que surge e se desenvolve e frente a grupos e setores a que beneficia", passa a "postular a necessidade de vincular a atividade científica aos processos gerais de transformação sócio-política” (GAJARDO, 1986, p. 15), daí a vocação política característica da linha crítico-emancipatória, voltada para os interesses sociais e objetivos vinculados à transformação da realidade injusta que atinge os países subdesenvolvidos.

Um outro aspecto sob a qual vale observação refere-se à natureza das relações estabelecidas entre o pesquisador (ou grupo de pesquisa) e os participantes envolvidos. Por exemplo, no caso de uma PA que articule uma escola e pesquisadores da universidade, é preciso pensar num trabalho de "mão-dupla", de forma que a interação desenvolvida entre as partes construa transformações tanto na escola participante, quanto na instituição visitante. Neste sentido, quando pensamos em projetos de PA, podemos vislumbrar interessantes contribuições no tocante a produção de conhecimentos que impliquem mudanças nas práticas e processos que caracterizam tanto a instituição visitante quanto aquela que recebe o projeto.

Quanto à diversidade de formatos de PA, verificamos quadro de falta de consenso entre os autores. Barbier (2007), por exemplo, entre outros tipos, menciona a pesquisa-ação integral formulada por André Morin (2004), além de propor e defender sua própria linha de PA: a pesquisa-ação existencial. Franco (2005) observa, em recentes trabalhos, pelo menos três distintas propostas: (i) pesquisa-ação colaborativa; (ii) pesquisa-ação crítica; (iii) pesquisa-ação estratégica. Em alguns casos, a exemplo da classificação proposta por Franco (2005), o elemento de 
distinção entre essas várias correntes está centrado na posição ocupada pelo pesquisador durante o processo. Em outros, como é o caso da linha que estamos assumindo aqui, parece que o critério de distinção está essencialmente ligado aos objetivos e intencionalidades da proposta desenvolvida (pragmáticos ou crítico/emancipatórios).

Voltando às suas principais características, como já foi explicitado, a PA é modalidade que pressupõe horizontalidade entre os sujeitos envolvidos. É uma forma de pesquisa visceralmente participativa, a ponto de alguns autores, como Barbier (2007), por exemplo, defenderem a ideia de pesquisador-coletivo: sujeitos e pesquisadores interagem na produção de diagnósticos, ações, reflexões, etc. Como diria o autor "não há pesquisa-ação sem participação coletiva" (BARBIER, 2007, p. 70). É importante salientar este ponto: os problemas de pesquisa e suas conexões com os problemas a serem atacados não podem ser impostos pelos pesquisadores. Com efeito, a definição dos problemas e objetivos da ação deve ser empreitada mediada e assessorada pelos pesquisadores, mas definida em quadro de partilha entre pesquisadores e os sujeitos envolvidos (BARBIER, 2007; MORIN, 2004; THIOLLENT, 2011). Por isso, alguns autores sublinham a ideia de contrato como elemento essencial da PA (DIONNE, 2007; MORIN, 2004). O contrato é uma espécie de acordo negociado entre as partes em regime de diálogo, estabelecendo aspectos diversos a envolver os processos gerados no contexto da PA a ser desenvolvida, passando pelos detalhes inerentes à imersão e aceitação do pesquisador pelo grupo/instituição, a definição dos papéis, processos e tarefas a serem desempenhados pelos atores, os objetivos e metas priorizados pelo coletivo, a lógica que comandará as tomadas de decisão ao longo do projeto, até as formas de avaliação e publicização dos resultados alcançados.

A ação a ser desencadeada corresponde aquilo que é necessário ser feito (ou transformado) para a solução do problema e "ocorre somente se for do interesse dos grupos e concretamente elaborada e praticada por eles" (THIOLLENT, 2011, p. 80).

Em termos de etapas a serem desenvolvidas, as diversas fases da PA podem ser amparadas no conhecido esquema de ciclo em espiral, envolvendo processos de reflexão - ação - reflexão ${ }^{7}$, inspirado na proposta de Lewin: "de planejamento, de ação, de observação, de reflexão, depois um novo planejamento da experiência em curso" (BARBIER, 2007, p. 60). Carr e Kemmis (1986) mencionam que os processos contidos nas espirais reflexivas vão se abrindo, no sentido de que as reflexões e ações vão se tornando cada vez mais abrangentes, além de mais aprofundadas. Temos também as etapas propostas por Thiollent (2011), que podem ter naturezas diversas: educativa, formativa, diagnosticadora, técnica, comunicativa, conscientizadora, política, cultural etc. Tais etapas poderiam ser sumariamente explicitadas numa organização da investigação que passa pela própria concepção e definição das prioridades de pesquisa, do desenrolar das atividades propostas e da avaliação das ações planejadas (ver Figura 3).

\footnotetext{
${ }^{7}$ Alguns autores preferem escrever "ação-reflexão-ação", aludindo ao fato de que se parte de uma ação já existente (vivenciada pelos próprios participantes) para daí desencadear o processo reflexivo e analítico, que culmina em ações de transformação. Outros preferem escrever "ação-reflexão-ação-reflexão..." (com as reticências) para indicar que o processo é contínuo e cíclico. Qualquer que seja a opção, deve-se considerar que "ação" e "reflexão" são etapas que se configuram e se constituem numa perspectiva dialética, ou seja, não existe uma sem a outra, nem quem antecede ou dispara quem, nem quem sucede quem. Configuram-se simultaneamente e na interdependência mútua, têm "existência" somente na existência da outra.
} 
Segundo El Andaloussi (2004, p. 86) a PA passa por etapas nas quais temos que "diagnosticar uma situação, iniciar uma ação, acompanhá-la, observá-la, conferir-lhe sentido, avaliando-a e incitando-a a desencadear novas ações"; e todo o processo se repete até a decisão final - pelos envolvidos no processo - da conclusão e resolução do problema concebido. Na mesma linha Dionne (2007, p. 22), didadicamente, menciona quatro fases principais para os processos envolvidos em uma PA: “i) identificação das situações iniciais; ii) projetação da pesquisa e da ação; iii) realização das atividades previstas; iv) avaliação dos resultados obtidos”. A vantagem no uso de algumas das variações desses modelos em espiral é que eles permitem ajustes e adequações nos rumos definidos para o processo de ação e busca da solução de problemas. Neste sentido, a PA é "biodegradável": não pode ser projeto inteiramente planejado, definido ou predeterminado a priori. O processo "deve ser, então, o mais aberto e flexível possível para que se possa adequar à trajetória seguida pelo pesquisador e pelos atores” (EL ANDALOUSSI, 2004, p. 109).

Figura 3. Etapas para formulação de projetos em pesquisa-ação

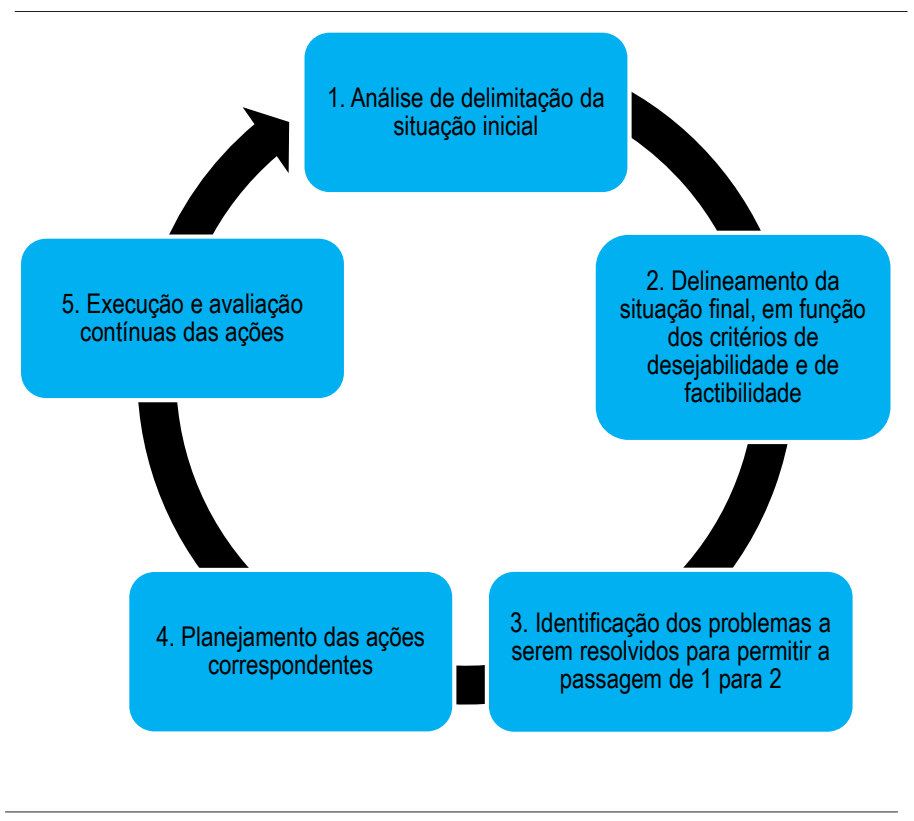

Fonte: adaptada de Thiollent (2011).

Em relação a detalhes relativos à produção de dados, dada a complexidade dos processos que envolvem a PA, o interessante é utilizar múltiplas estratégias e recursos, incluindo o expediente da observação participante, técnicas de dinâmica grupal, recolha de documentos, grupos focais, entrevistas individuais, etc. O importante é produzir dados e informações em diferentes ângulos e perspectivas, procurando construir uma visão holística do processo desenrolado durante o projeto, envolvendo a dimensão qualitativa e interpretativa. 
Embora os pesquisadores não assumam, como em outras modalidades de pesquisa, o papel central na definição dos rumos do processo investigativo, já que a definição da prioridade dos problemas a serem tratados depende de processos interativos e dialógicos entre pesquisadores e sujeitos implicados, eles "desempenham um papel ativo no equacionamento dos problemas encontrados, no acompanhamento e na avaliação das ações desencadeadas em função dos problemas" que a investigação deseja atacar (THIOLLENT, 2011, p. 21). Neste sentido, no contexto de desenvolvimento do processo de PA, os pesquisadores profissionais são chamados de mediadores, motivadores, orientadores, assessores, animadores, etc. (BARBIER, 2007; DEMO, 2004). Devemos lembrar que existem inúmeros casos ilustrados na literatura sobre o desenvolvimento de PA fora do contexto acadêmico ${ }^{8}$, onde a figura do pesquisador assume, inclusive, papel secundário. Em outras ocasiões, o processo é disparado pelo grupo/ comunidade interessada, que pode acionar o(s) pesquisador(es) em algum momento e até dispensar sua participação em outro. Mas, pensando nos projetos de PA desenvolvidos por conta da realização de estudos acadêmicos, a exemplo das pesquisas que dão origem às dissertações e teses, os desafios se amplificam, dadas as limitações de tempo, sobretudo no mestrado, e demais exigências do design singular dos projetos de PA.

Talvez isso explique a escassez de estudos de PA na área de Educação em Ciências, hipótese que estamos assumindo aqui e que precisa ser confirmada em estudos que realizaremos posteriormente. É possível que as dinâmicas atuais caracterizadoras da formação de mestres e doutores, incluindo fatores como a limitação de tempo, espaço e recursos humanos e financeiros estabeleçam óbices para a realização de projetos dessa natureza. Há também aqueles que argumentam que dada a complexidade da PA, dificilmente ela poderia "ser empreendida por pesquisadores iniciantes" (GHEDIN; FRANCO, 2008). Assim, dentro dessa perspectiva, considerando os problemas apontados, haveria mais espaço para o desenvolvimento de projetos de PA considerando os grupos de pesquisa já consolidados, que podem assumir projetos de pesquisa mais amplos e perenes, aproveitando a expertise acumulada pelos seus pesquisadores. Todavia, essa é uma questão controversa, que precisa ter discussão aprofundada dentro da área.

Para aqueles que desejam enveredar nos caminhos da PA, na sequência, o Quadro 1, formulado conforme aportes encontrados na literatura, apresenta uma lista não exaustiva de características, reunindo aspectos básicos para delimitação de projetos dessa natureza em instituições escolares da educação básica ou universitárias, ou ainda em contextos não formais de educação.

\footnotetext{
${ }^{8}$ Ver, por exemplo, Bogdan e Biklen (2010).
} 
Quadro 1. Síntese de características básicas para delineamentos de projetos de Pesquisa-Ação

\begin{tabular}{|c|}
\hline Características básicas de projetos de Pesquisa-Ação \\
\hline $\begin{array}{l}\text { Criticam a cultura acadêmica e científica ortodoxa, a separação entre teoria e prática; rejeitam noções } \\
\text { positivistas aplicadas à prática de pesquisa. }\end{array}$ \\
\hline $\begin{array}{l}\text { Na pesquisa-ação não se trabalha sobre os outros, mas sim, com os outros; além de realizar a } \\
\text { investigação de seu interesse, por vezes, centrada no monitoramento do processo, o pesquisador } \\
\text { deve se concentrar nos interesses do grupo/ coletividade. }\end{array}$ \\
\hline $\begin{array}{l}\text { O problema a ser estudado está localizado na comunidade, localidade de trabalho, instituição, etc.; é } \\
\text { problema que envolve as pessoas, professores, estudantes, funcionários, direção, podendo focalizar } \\
\text { grupos específicos dentro do contexto escolar ou mesmo a escola como um todo. A comunidade } \\
\text { deve estar no controle do processo; controle compartilhado com o(s) pesquisador(es). }\end{array}$ \\
\hline A seleção dos problemas a serem atacados emerge do grupo/população participante. \\
\hline $\begin{array}{l}\text { É orientada em função da resolução de problemas e/ou objetivos de transformação e mudança } \\
\text { social. }\end{array}$ \\
\hline $\begin{array}{l}\text { É processo coletivo: "A população pesquisada é motivada a participar da pesquisa como agente ativo, } \\
\text { produzindo conhecimento" e intervindo na sua própria realidade (DEMO, 2004, p. 43). }\end{array}$ \\
\hline $\begin{array}{l}\text { É participativa: os rumos do projeto são definidos em quadro de partilha entre pesquisadores } \\
\text { e sujeitos. O pesquisador não pode definir isoladamente os objetivos, ações e demais } \\
\text { encaminhamentos do trabalho a ser realizado, portanto, há a necessidade de se estabelecer um } \\
\text { espaço de natureza deliberativa para definição dos rumos do processo (DEMO, 1999, 2004; } \\
\text { MORIN, 2004). }\end{array}$ \\
\hline O planejamento de trabalho é flexível e ajustável ao longo do tempo. \\
\hline $\begin{array}{l}\text { "A relação sujeito e objeto é dialética, do que segue que não há propriamente "objeto", mas } \\
\text { parceiros da mesma jornada" (DEMO, 2004, p. 89). Assim, o processo "deve ser baseado em sistema } \\
\text { de discussão, investigação e análise, em que os "investigados” formam parte do processo ao mesmo } \\
\text { nível do investigador" (DEMO, 2004, p. 96). }\end{array}$ \\
\hline $\begin{array}{l}\text { A PA “requer um contrato aberto e formal (preferencialmente não estruturado), implicando em } \\
\text { participação cooperativa e podendo levar até a co-gestão" (MORIN, 2004, p. 60). }\end{array}$ \\
\hline $\begin{array}{l}\text { É experiência educativa ou pedagógica, dado que os participantes, no decorrer do processo, } \\
\text { incrementam seu potencial de análise sobre a situação em que vivem/trabalham e cultivam } \\
\text { elementos para problematizá-la e mudá-la no sentido desejado. Em outras situações tem caráter } \\
\text { conscientizador e gera compromissos e engajamento em processos de mudança (DEMO, 2004). }\end{array}$ \\
\hline $\begin{array}{l}\text { A interpretação e análise são produto de discussões coletivas, exigindo uma estrutura de linguagem } \\
\text { acessível a todos (BARBIER, 2007). }\end{array}$ \\
\hline $\begin{array}{l}\text { O processo de pesquisa não se esgota em mero produto acadêmico; deve representar benefício à } \\
\text { comunidade envolvida, isto é, deve ter alguma utilidade prática de natureza social (DEMO, 1999, } \\
\text { 2004) e/ou emancipatória. }\end{array}$ \\
\hline
\end{tabular}

Fonte: elaborado pelos autores.

\section{As outras modalidades de pesquisas de natureza interventiva}

A seguir, para complementar o esquema apresentado na Figura 2, faremos uma breve descrição no sentido de explicitar características que demarcam as outras modalidades de pesquisas de natureza interventiva (PNI).

a) Pesquisas de Aplicação: investigações baseadas em projetos nas quais as prioridades de investigação são definidas integralmente pelos pesquisadores. Envolvem o planejamento, a 
aplicação (execução) e a análise de dados sobre o processo desenvolvido, em geral, tentando delimitar limites e possibilidades daquilo que é testado ou desenvolvido na intervenção. Os processos são fundamentados em teorias ou outros referenciais do campo específico de estudo. Os objetivos não estão necessariamente voltados para a transformação de uma realidade, mas sim, amiúde, dar contribuições para a geração de conhecimentos e práticas, envolvendo tanto a formação de professores, quanto questões mais diretamente relacionadas aos processos de ensino e aprendizagem, como a testagem de princípios pedagógicos e curriculares (interdisciplinaridade, contextualização, transversalidade, avaliação etc.) e recursos didáticos. Como parte dos trabalhos desenvolvidos nesta modalidade temos pesquisas buscando informações e dados empíricos relativos ao teste de sequências e estratégias didáticas, oficinas, unidades de ensino, materiais didáticos, propostas de programas curriculares, cursos e outros processos formativos, etc. $\mathrm{Na}$ classificação proposta por Franco (2005) e Ghedin e Franco (2008), as aqui denominadas de Pesquisas de Aplicaşão estariam próximas daquilo que os referidos autores chamam de pesquisa-ação estratégica. Não concordamos com essa denominação pois preferimos reservar o termo "pesquisa -ação" (adjetivado ou não) somente para processos cujo delineamento metodológico envolva, de fato, todos os participantes como pesquisadores, resultando num efetivo processo colaborativo.

Já na diversidade de pesquisas apresentadas por Barbier (2007), teríamos o que o renomado autor chama de ação-pesquisa:

[...] processo induzido pelos pesquisadores, em função de modalidades que eles propõem, a pesquisa é efetuada pelos autores em situação e sobre a situação destes. A ação parece prioritária nesse tipo de pesquisa, mas as consequências da ação permitem aos pesquisadores explorá-las com fins de pesquisa mais acadêmica (p. 43).

Entretanto, se utilizarmos Chizzotti (2006, p. 80), dentro de uma concepção associada às pesquisas qualitativas em educação, estaríamos próximos de "uma pesquisa sobre a ação quando se trata de estudá-la para compreendê-la e explicar seus efeitos”.

Portanto, nesta modalidade, os interesses de investigação estão confinados nas mãos dos pesquisadores. Outras pessoas, como alunos e professores, podem participar dos processos interventivos gerados no âmbito da investigação, mas como sujeitos investigados e/ou beneficiários das propostas testadas. De qualquer forma, mesmo considerando que os sujeitos não são alçados à condição de pesquisadores, é importante nesses casos, que os investigadores procurem captar a perspectiva desses sujeitos sobre o processo desenvolvido (BOGDAN; BIKLEN, 2010; FRANCO, 2005).

b) Pesquisas sobre a própria prática: Ghedin e Franco (2008, p. 237) assinalam o caso de pesquisas em que o pesquisador, trabalhando em projeto individual, "investiga seu próprio local e função de trabalho". Pode envolver um professor, uma diretora, um coordenador pedagógico, etc. Portanto, são projetos que não apresentam a dimensão coletiva mencionada anteriormente quando nos referimos a pesquisa-ação. Um exemplo dessa modalidade é encontrado em algumas pesquisas sobre identidade profissional docente, onde professores pesquisam a própria prática para identificar detalhes inerentes a sua atuação profissional e dificuldades, avanços e outros pontos relativos ao desenvolvimento profissional. Há casos em que os próprios professores desenvolvem sequências didáticas ou unidades de ensino e testam seus 
efeitos nas aulas que conduzem junto a estudantes da educação básica e/ou licenciandos em formação para a docência. Contudo, nessas situações, o foco investigativo reside na mudança de prática do professor-pesquisador e não sobre o produto didático elaborado e seus efeitos sobre a aprendizagem dos estudantes como ocorre nas pesquisas de aplicação.

Segundo Morin (2004, p. 22), "percebe-se entre os docentes uma vontade de enriquecer seus conhecimentos para enfrentar a complexidade dos problemas encontrados". O autor dá vários exemplos, entre os quais o de um professor insatisfeito com seu ensino. "A mudança almejada poderia ser uma pedagogia mais centrada em projetos de estudo dos educandos" (MORIN, 2004, p. 116). Então, parece que a ideia de investigar a própria prática parte da constatação da necessidade de mantermos um plano de formação e atualização para carreira docente que seja alternativo às propostas tecnicistas e neo-tecnicistas, sobretudo aquelas que retiram a autonomia dos professores (racionalidade técnica). As pesquisas nesta área estão envolvidas em processos de compreensão e melhoria do trabalho docente, começando pela reflexão sobre a própria prática e experiências profissionais. Partem também da ideia de que é preciso, primeiramente, dar conta das insuficiências geradas na formação inicial do profissional e, depois, diante das múltiplas demandas geradas para os professores no contexto educacional atual, gerar uma disposição para investigar o próprio trabalho, e para se aperfeiçoar com o passar do tempo. Um compromisso de ajudar os profissionais a serem responsáveis por sua própria formação profissional (MORIN, 2004; ZEICHNER; DINIZ-PEREIRA, 2006).

c) Pesquisas Experimentais: são caracterizadas por manipularem diretamente variáveis relacionadas com o objeto de estudo, gerando situações de interferência numa determinada realidade ou fenômeno vinculado diretamente à realidade, manipulando-se a variável independente a fim de observar o que acontece com a dependente. Segundo Laville e Dionne (1999, p. 139), para uma pesquisa ser considerada do tipo experimental:

[...] deve inicialmente visar a demonstrar a existência de uma relação de causa e efeito entre duas variáveis. Essa demonstração apoia-se em uma experiência na qual o pesquisador atua sobre a variável independente associada à causa para, em seguida, medir os efeitos engendrados no plano da variável dependente.

Neste sentido, as pesquisas experimentais pretendem explicar de que modo ou por que causas o fenômeno é produzido ou alterado em função da ação da variável (independente) introduzida no processo examinado durante a investigação. Essa ideia é corroborada por Morin (2004, p. 70), que assinala que "a pesquisa experimental [...] produz efeitos relacionados com suas variáveis independentes. Trata-se de uma relação de causa e efeito; sua finalidade é, sobretudo em educação, a verificação de hipóteses, geralmente derivadas de teoria".

No passado, os pesquisadores assumiam a possibilidade de se isolar e controlar as variáveis independente e dependente durante a realização da intervenção. $\mathrm{Na}$ atualidade, reconhece-se tal impossibilidade, uma vez que inúmeras variáveis podem interferir no processo investigado durante seu transcorrer. Assim, os resultados não podem ser generalizados ou atribuídos exclusivamente aos efeitos da variável independente escolhida sobre a variável dependente. Pode-se, contudo, concluir por efeitos positivos (ou negativos) de uma sobre a outra, mas não atribuir tais resultados exclusivamente à variável independente. 
Para Megid Neto (1999, p. 122), as pesquisas experimentais referem-se a estudos de “descrição e análise de experimentos, em que, em condições controladas, uma ou mais variáveis são introduzidas no processo, sendo manipuladas e controladas pelo pesquisador". Há variados desenhos que essas pesquisas podem assumir: grupo experimental e grupo controle homogêneos; grupo experimental e grupo controle não homogêneos (pesquisas "quase-experimentais"); grupo experimental único (sem grupo controle) submetido a pré-teste e pós-teste ou a testes intermediários no decorrer do processo etc. Vêm crescendo o modelo de pesquisa experimental de grupo único no campo da pesquisa em Educação em Ciências no Brasil, principalmente a partir da década de 2000. Muitas vezes é confundido equivocadamente com "estudo de caso" ou mesmo com "pesquisa-ação" pelos próprios autores dos trabalhos. Devemos ressaltar que, embora haja ausência de grupo controle, este ocorre com base nos testes de avaliação (préteste e pós-teste) ou nos testes anteriores ou posteriores ao longo do processo de investigação. Ou seja, substitui-se a figura do grupo controle (homogêneo ou não homogêneo ao grupo experimental) pelo monitoramento contínuo dos estágios de desenvolvimento dos sujeitos participantes da pesquisa.

Em linhas gerais, pesquisas experimentais, em função de suas características, se aproximam dos métodos empregados nas Ciências Naturais, ou, no caso das Ciências Humanas, do paradigma positivista de pesquisa, ou se alinham às atuais perspectivas pós-positivistas, com a adoção de grupos controle e experimentais, de preferência, selecionados aleatoriamente, pré e pós-testes, tratamento estatístico de dados, separação entre sujeito (pesquisador) e objeto, preocupações com validação interna e externa dos experimentos, e com a generalização das conclusões obtidas no estudo realizado. Uma tipologia para delineamento desses trabalhos pode ser encontrada na obra de Campbell e Stanley (1979) ou ainda em Laville e Dionne (1999). Em nosso caso, distinguimos as Pesquisas Experimentais das Pesquisas de Aplicação justamente por esse caráter mais aderido das primeiras à ortodoxia positivista ou, de modo mais frequente na atualidade, ao paradigma pós-positivista.

d) Pesquisa \& Desenvolvimento: esse tipo de pesquisa é vinculado a estudos de investigação caracterizados da seguinte forma:

\footnotetext{
[...] desenvolvimento e testagem de novos processos ou produtos (projetos, manuais, cartilhas, textos, materiais didáticos, metodologias etc.). [...] esse tipo de pesquisa parte de um problema identificado, geralmente de natureza mais prática e cuja tentativa de solução se faz imediata; o pesquisador [...] lança-se ao desenvolvimento (produção) de um determinado produto ou processo que viabilize a solução do problema (SEVERINO, 1986 apud MEGID NETO, 2014, p. 108).
}

Denominadas no contexto internacional por Research and Development, elas têm caráter marcadamente aplicado, sendo, portanto, empregadas no contexto da produção e desenvolvimento de produtos e processos (BORG; GALL, 1989; CHARLES, 1988).

Temos optado mais recentemente pela denominação de pesquisas de desenvolvimento de processos e produtos, ou mais sucintamente pesquisa de desenvolvimento. De modo distinto das pesquisas de aplicação, cujo foco reside na descrição e análise da aplicação de um produto ou processo, ou das pesquisas experimentais, cujo foco é colocado no controle de variáveis quando da aplicação 
de um processo ou produto; as pesquisas de desenvolvimento têm seu foco na descrição e análise do processo de desenvolvimento do produto ou processo. O relatório de pesquisa, por exemplo, sob a forma de dissertação ou tese acadêmica, assenta-se na descrição detalhada de todo esse processo de desenvolvimento. Deve conter fundamentação sobre a linha teórica (pedagógica, sociológica, filosófica etc.) assumida no processo ou produto elaborado, e também revisão bibliográfica sobre trabalhos similares. O tradicional capítulo metodológico da pesquisa consiste na apresentação, com minúcias, das etapas de desenvolvimento do processo ou produto. $\mathrm{Na}$ sequência, o capítulo de dados e resultados aporta a descrição efetiva do trabalho prático realizado, desde a concepção do processo ou produto, seu desenvolvimento e finalização, incluindo os acertos e "erros" cometidos e as mudanças de rumo porventura ocorridas. Além do desenvolvimento do material ou processo, muitos pesquisadores realizam a testagem de sua aplicação em situação real, relatando os efeitos positivos alcançados, as limitações e dificuldades encontradas entre outros aspectos. Essa aplicação não se constitui em condição obrigatória para a validade científica da pesquisa, embora uma parte considerável dos trabalhos da atualidade, sobretudo em cursos de mestrado profissional, realizem essa aplicação.

Outra denominação encontrada na literatura refere-se ao termo Design Science Research, utilizado em áreas como gestão, sistemas de informação e engenharia, mas ainda pouco explorada nas pesquisas educacionais. Segundo Dresch, Lacerda e Antunes Júnior (2015, p. 67) essa modalidade busca, "a partir do entendimento do problema, construir e avaliar artefatos que permitam transformar situações, alterando suas condições para estados melhores ou desejáveis". Tais artefatos configuram-se como produtos, processos, softwares, modelos, métodos, etc. Para os referidos autores é o método indicado quando o "objetivo é projetar e desenvolver artefatos, bem como soluções prescritivas, seja em um ambiente real ou não" (DRESCH; LACERDA; ANTUNES JÚNIOR, 2015, p. 95).

\section{Considerações finais}

Em linhas gerais, desejamos com este artigo orientar pesquisadores interessados em desenvolver Pesquisas de Natureza Interventiva (PNI). Para isso, foi preciso mostrar as múltiplas facetas assumidas pelas pesquisas articuladoras de ação e pesquisa, e, mais que isso, tentar problematizar o uso vago e indiscriminado do termo Pesquisa-Ação, bem como diferenciar essa modalidade de pesquisa de outras pesquisas que envolvem ações investigativas (pesquisa de aplicação, pesquisa experimental, pesquisa \& desenvolvimento).

Em síntese as Pesquisas de Aplicação centram foco na aplicação do produto e processo, mas sem preocupação com o controle de variáveis; as Pesquisas \& Desenvolvimento colocam o foco no relato e análise do processo de desenvolvimento do produto ou processo; e as Pesquisas Experimentais no controle de variáveis e análise das relações de causa-e-efeito. Então, no caso dessas três modalidades, temos a elaboração de algum processo ou produto educacional (sequência didática, material didático etc.), mas cada uma delas centra a atenção - e o problema de pesquisa - num dos três pontos supracitados.

Outra consequência dos argumentos aqui explicitados foi apontar a PA com uma fração dos possíveis trabalhos encontrados entre as PNI, sendo caracterizada segundo pressupostos defendidos e encontrados na própria literatura, sobretudo em autores consagrados pela 
abordagem da temática. Por isso, parte significativa do texto foi dedicado a buscar na literatura pertinente, critérios para definirmos de forma mais precisa o que é uma Pesquisa-Ação. Como produto da revisão de literatura realizada, chegamos a pelo menos duas modalidades ou tradições de PA. A primeira centrada na dimensão pragmática e instrumental, ou como diria Thiollent (1999), sociotécnica, empenhada em gerar projetos que atuam no diagnóstico de problemas de natureza mais pontual e na realização de processos voltados para mudanças no sentido da melhoria da organização de instituições, da formação e das práticas de grupos de professores, sempre buscando a melhoria da qualidade profissional e educativa. Nosso palpite é que, talvez, essa seja a forma mais usual de pesquisa-ação realizada na área de Educação em Ciências, sobretudo nos projetos vinculados à formação de professores.

A outra modalidade, caracteriza-se pelo engajamento político mais radical, centrado em objetivos de dimensão crítico-emancipatória, buscando processos geradores de conscientização sociopolítica que, por um lado, atuam na diagnose de problemas que afetam esses grupos e instituições sociais e, por outro, mobilizam as pessoas em torno da resolução desses problemas. É como se paulatinamente, ao longo do processo de PA, o coletivo, passe a conquistar qualidade política em suas ações (cidadania), envidando esforços na luta por diversas demandas de interesse, seja no sentido de questões mais específicas (melhores condições salariais e de trabalho, reconhecimento social, organização mais democrática/participativa da escola, articular a escola com a comunidade), seja no sentido de questões mais amplas, que dizem respeito à educação, serviços públicos, ética e governança responsável no trato das coisas públicas, políticas públicas e representação social etc.

Por fim, a matriz esboçada na Figura 2 e detalhada nas seções subsequentes do texto, permite um enquadramento mais adequado para diversas pesquisas desenvolvidas dentro da área. Embora sua apresentação tenha caráter preliminar, pensamos que ela pode ser orientadora no sentido de evitar confusões existentes em torno da pesquisa-ação e suas múltiplas facetas, assim como demarcar aspectos distintivos entre as demais modalidades de pesquisa aqui discutidas e a pesquisa-ação. É certo que há "possíveis diferenças de abordagem, ou mesmo divergências filosóficas, sempre inevitáveis” (DIONNE, 2007, p. 17), mas consideramos grave equívoco confundir pesquisa-ação com quaisquer outras modalidades de pesquisa aplicada.

\section{Agradecimentos}

Os autores agradecem a colaboração da Coordenação de Aperfeiçoamento de Pessoal de Nível Superior (CAPES) e da Fundação de Amparo à Pesquisa do Estado da Bahia (FAPESB).

\section{Referências}

ANDRÉ, M. E. D. A. Pesquisa em educação: desafios contemporâneos. Pesquisa em Educação Ambiental, Ribeirão Preto, v. 1, n. 1, p. 43-57, 2006. Disponível em: < https:// doi.org/10.11606/issn.2177-580X.v1i1p43-57>. Acesso em: 20 out. 2017. 
BARBIER, R. A pesquisa-ação. Brasília, DF: Líber, 2007.

BOGDAN, R.; BIKLEN, S. Investigação qualitativa em educação: uma introdução à teoria e aos métodos. Porto: Porto Editora, 2010.

BORG, W. R.; GALL, M. D. Educational research: an introduction. New York: Longman, 1989.

BRANDÃO, C. R. A pesquisa participante e a participação da pesquisa: um olhar entre tempos e espaços a partir da América Latina. In: BRANDÃO, C. R.; STRECK, D. R.

Pesquisa participante: o saber da partilha. Aparecida: Ideias \& Letras, 2006. p. 21-54.

BRANDÃO, C. R.; STRECK, D. R. Pesquisa participante. Aparecida: Ideias \& Letras, 2006.

CAMPBELL, D. T.; STANLEY, J. C. Delineamentos experimentais e quase experimentais de pesquisa. São Paulo: EPU, 1979.

CARR; W. W.; KEMMIS; S. Becoming critical: education, knowledge and action research. London: Deakin University Press, 1986.

CHARLES, C. M. Introduction to educational research. New York: Longman, 1988.

CHIZZOTTI, A. Pesquisa qualitativa em ciências humanas e sociais. Petrópolis: Vozes, 2006.

DEMO, P. Elementos metodológicos da pesquisa participante. In: BRANDÃO, C. R. (Org.). Repensando a pesquisa participante. São Paulo: Brasiliense, 1999. p. 104-130.

Pesquisa participante: saber pensar e intervir juntos. Brasília, DF: Lỉber, 2004.

DIONNE, H. A pesquisa-ação para o desenvolvimento local. Brasília, DF: Líber, 2007.

DRESCH, A.; LACERDA, D. P.; ANTUNES JR, J. A. Design science research: método de pesquisa para avanço da ciência e tecnologia. Porto Alegre: Bookman, 2015.

DUBOST, J. Intervention psycho-sociologique. Paris: PUF, 1987.

EL ANDALOUSSI, K. Pesquisas-ações: ciências, desenvolvimento, democracia. São Carlos: EdUFSCar, 2004.

FERREIRA, A. B. H. Novo Aurélio século XXI. Rio de Janeiro: Nova Fronteira, 1999.

FRANCO, M. A. S. Pedagogia da pesquisa-ação. Educação e Pesquisa, São Paulo, v. 31, n. 3, p. 483-502, 2005. Disponível em: <https://doi.org/10.1590/S151797022005000300011 >. Acesso em: 20 out. 2017.

GAJARDO, M. Pesquisa participante na América Latina. São Paulo: Brasiliense, 1986.

GATTI, B. A produção da pesquisa em educação no Brasil e suas implicações socio-

político-educacionais: uma perspectiva da contemporaneidade. In: CONFERÊNCIA DE PESQUISA SÓCIO-CULTURAL, 3., 2000, Campinas. Disponível em: < http:/ /www.lite. fe.unicamp.br/cursos/txt8.htm>. Acesso em: 20 out. 2017. 
GHEDIN, E.; FRANCO, M. A. S. Questões de método na construção da pesquisa em educação. São Paulo: Cortez, 2008.

GREENWOOD, D. J.; LEVIN, M. Reconstruindo as relações entre as universidades e a sociedade por meio da pesquisa-ação. In: DENZIN, N. K. et al. O planejamento da pesquisa qualitativa: teorias e abordagens. Porto Alegre: ArtMed, 2006. p. 91-113.

HOUAISS, A.; VILLAR, M. S. Dicionário Houaiss da língua portuguesa. Rio de Janeiro: Objetiva, 2009.

LAVILLE, C.; DIONNE, J. A construção do saber. Belo Horizonte: UFMG, 1999.

MC KERNAN, J. Curriculum action research: a handbook of methods and resources for the reflective practitioner. London: Kogan Page, 1996.

MEGID NETO, J. Origens e desenvolvimento do campo de pesquisa em educação em ciências no Brasil. In: NARDI, R.; GONÇALVES, T. V. O. A pós-graduação em ensino de ciências e matemática no Brasil. São Paulo: ELF, 2014. p. 98-139.

. Tendências da pesquisa acadêmica sobre o ensino de ciências no nível fundamental. 1999. 114f. Tese (Doutorado em Educação) - Faculdade de Educação, Universidade Estadual de Campinas, Campinas, 1999.

MICHAELIS. Moderno dicionário da língua portuguesa. São Paulo: Melhoramentos, 1998.

MIRANDA, M. G.; RESENDE, A. C. A. Sobre a pesquisa-ação na educação e as armadilhas do praticismo. Revista Brasileira de Educação, Rio de Janeiro, v. 11, n. 33, p. 511-18, 2006. Disponível em: <https://doi.org/10.1590/S1413-24782006000300011>. Acesso em: 20 out. 2017.

MORIN, A. Pesquisa-ação integral e sistêmica. Rio de Janeiro: DP\&A, 2004.

SILVA, M. O. S. Refletindo a pesquisa participante. São Paulo: Cortez, 1991.

THIOLLENT, M. Metodologia da pesquisa-ação. São Paulo: Cortez, 2011.

. Notas para o debate sobre pesquisa-ação. In: BRANDÃO, C. R. (Org.).

Repensando a pesquisa participante. São Paulo: Brasiliense, 1999. p. 82-103.

TRIPP, D. Pesquisa-ação: uma introdução metodológica. Educação e Pesquisa, São Paulo, v. 31, n. 3, p. 443-466, 2005. Disponível em: < https://doi.org/10.1590/S151797022005000300009>. Acesso em: 20 out. 2017.

ZEICHNER, K. M.; DINIZ-PEREIRA, J. E. Pesquisa dos educadores e formação docente voltada para a transformação social. Cadernos de Pesquisa, São Paulo, v. 35, n. 125, p. 63-80, 2005. Disponível em: <https://doi.org/10.1590/S0100-15742005000200005 >. Acesso em: 20 out. 2017. 
Teixeira, P. M. M.; Megid Neto, J.

Artigo recebido em 27/09/2016. Aceito em 18/04/2017.

Endereço para contato: UESB, DCB, Av. José Moreira Sobrinho, s/n, Jequiezinho, CEP 45206-190, Jequié, BA, Brasil. 